\title{
Experimental Analysis on Safety System of a Simulated Small Scale Pressurized Water Reactor System with Intelligent Control
}

\author{
Md. Shakerul Islam, Altab Hossain*, Khalid Mursed, and Rafi Alam Chowdhury \\ Department of Nuclear Science and Engineering, Military Institute of Science and Technology (MIST), Dhaka, Bangladesh \\ emails: shakerul@nse.mist.ac.bd; ${ }^{*}$ altab76@gmail.com; murshedy2k@gmail.com; and arrafialam@gmail.com
}

\section{ARTICLE INFO}

Article History:

Received: 14th April 2020

Revised: $17^{\text {th }}$ June 2020

Accepted: 05th August 2020

Published: $16^{\text {th }}$ December 2020

\section{Keywords:}

Water-based reactor Intelligent control Thermal hydraulic Heat transfer Safety

\begin{abstract}
A B S T R A C T
Reactors are widely used in the nuclear power plant due to the rapid demand for electricity by reducing the greenhouse effect. However, the effectiveness of the nuclear reactor depends on an adequate safety system. Hence, temperature and heat transfer are two critical parameters for any reactor in operation for which intelligent temperature control with an integrated safety system is essential. Therefore, the present study has emphasized the development of a simulated small-scale water-based reactor with intelligent control and safety system and examined through the analysis of thermal-hydraulic parameters. Radial heat transfer of an electric rod used as fuel in the primary circuit has been analyzed by taking sensor reading in various positions of the core. The developed system is self-controlled with all possible active and passive safety systems. Consecutively, the prototype has also been designed including manual adjustment to ensure a fail-safe environment. The system is capable to operate at temperatures between $80^{\circ} \mathrm{C}$ and $120^{\circ} \mathrm{C}$, although the design can withstand up to $200^{\circ} \mathrm{C}$. The data of the experiment are taken under the pressure of $200 \mathrm{kPa}$ at $120^{\circ} \mathrm{C}$ temperature. Results show that heat output of $2116.09 \mathrm{~kJ}$ has been obtained from the system against heat input of $2514.80 \mathrm{~kJ}$, which gives an efficiency around $16 \%$ of the developed system.
\end{abstract}

(C) 2020 MIJST. All rights reserved.

\section{INTRODUCTION}

Fossil fuels used in conventional thermal power plants cause many environmental problems. But nuclear energy does not emit greenhouse gases unlike coal and natural gas and hence, they do not contribute to climate change. Since the world tries to reduce global warming, nuclear power plant (NPP) is contributing to the energy mix by generating a significant amount of electricity. In an increasingly carbon-constrained future, nuclear power is becoming recognized as an integral part of the world's low-carbon energy solution (Ho et al., 2019). Nuclear power has grown quickly in the 1970s and 1980s, reaching a global installed capacity of 396 GWe today (IAEA, 2019). It is found that the annual load factor of nuclear power in China is about $90 \%$, which is much higher than those of coal-fired power, wind power, and solar power (Zhen, 2016). It is noted that two types of light water reactors namely Pressurized Water Reactor (PWR) and Boiling Water Reactor (BWR), are commonly used in the world's nuclear power plants. However, one of the main differences between PWR and BWR is in the steam generation process. In general, PWR consisting of primary and secondary water circuit produces steam indirectly, whereas BWR consisting of a single water circuit produces steam directly. More precisely, in a PWR, the coolant being heat at high temperature using heat from the reactor core is forced to maintain its liquid form under high temperature due to high pressure. Subsequently, the heat produced from the primary water circuit is further transferred to the secondary circuit which turns into steam and rotates the turbine, thereby, producing electricity. On the other hand, in a BWR, steam produced directly by the boiling of water coolant is detached using steam separators placed above the reactor core, and thereby, rotating the turbine. Research shows that about $80 \%$ of operated nuclear power plants are of PWR and BWR typed light water reactor (Breeze et al., 2014). Ordinary water is used as coolant and moderator in BWR typed reactor in which, water is being boiled at the boiling point of $285^{\circ} \mathrm{C}$ at a pressure of $7.5 \mathrm{MPa}$, and the steam generated is used 
directly to operate a steam turbine. However, the accident at Three Mile Island (TMI) has led to an essential improvement in the safety of nuclear plants throughout the world. The investigation shows that the human element had not been adequately included in previous safety considerations, and this observation prompted numerous advances in design and operating practices at nuclear plants. Other notable changes in both hardware and practices were research stimulated by accident (Kojima et al., 2007). Nuclear power generated through a controlled chain reaction is controlled through the four-factor formula ( $\mathrm{P}^{\prime}$ al \& $\mathrm{P}^{\prime}$ azsit, 2009). If the reaction cannot be controlled, then there is a possible chance of occurring major anomaly. After the Chernobyl accident in 1986, the importance of containment for severer accidents became highlighted (Balonov, 2013). The reactor core was partially melted down, thereby, many radioisotopes was released as the consequence of the accident and many people were evacuated from the exclusion zone (Miller, 1994). Again, the nuclear accident that occurred in Fukushima Daiichi in Japan was mainly caused by a massive tsunami which made the station completely blackout (Khan et al., 2018). Accident management was practiced both at Three Mile Island and Chernobyl, with significant consequences in both cases. The investigation of the TMI and Chernobyl accident has shown the failure of the management processes which are supposed to have an adequate safety culture. In both cases, there were weaknesses in design, operating practices, training, and feedback of operating information, and there was no organized mechanism to ensure that weaknesses were recognized and corrected. The rate of civil nuclear accidents over time since 1952 has been decreased significantly from the 1970s, reaching to be a stable level of around 0.003 events per plant per year (Wheatley et al., 2016). After Fukushima nuclear accident in Japan, the elements such as transparency, acceptability and communication capacity of nuclear safety information have emerged as an important part of key elements for nuclear safety regulation since 2010 (Kim et al., 2019). The Chernobyl accident has led the International Safety Advisory Group (INSAG) to accelerate the preparation of INSAG-3. From all the accidents, one of the most important lessons has been learned that the control system of any reactor must be robust, efficient, and reliable at the same time. Several studies have been performed on nuclear reactor to ensure adequate safety, temperature control with an integrated safety system (Gharib et al., 2011; Hossain et al., 2019; IAEA, 2002; Khan \& Islam, 2019; Sunday et al., 2013; Vojackova et al., 2017; Nain et al., 2019). The literature shows that the thermal-hydraulic models through hot channel fuel centreline temperature play a significant role to safety-related parameters within the design limit (Rahman et al, 2014). However, the investigation was performed using computer code and the data were far to compromise the safety of the reactor. Hence, experimental, and theoretical studies on heat transfer, intelligent control and safety system are very important for any nuclear reactor. Moreover, it is found that experimental studies are important for making a relationship between the flow rate and electrical power of the motor driving the pumps which must be addressed in a nuclear reactor. Therefore, this study has been performed with the development of a simulated small-scale water based PWR reactor. Furthermore, the analysis has been carried out to evaluate the heat transfer, safety, and control system of a working reactor model.

\section{MATERIALS AND METHODS}

A simulated small-scale water based PWR reactor shown in Figure 1 is developed considering three parts: (i) thermal hydraulics, (ii) safety system, and (iii) intelligent control system in the Nuclear Laboratory of MIST.

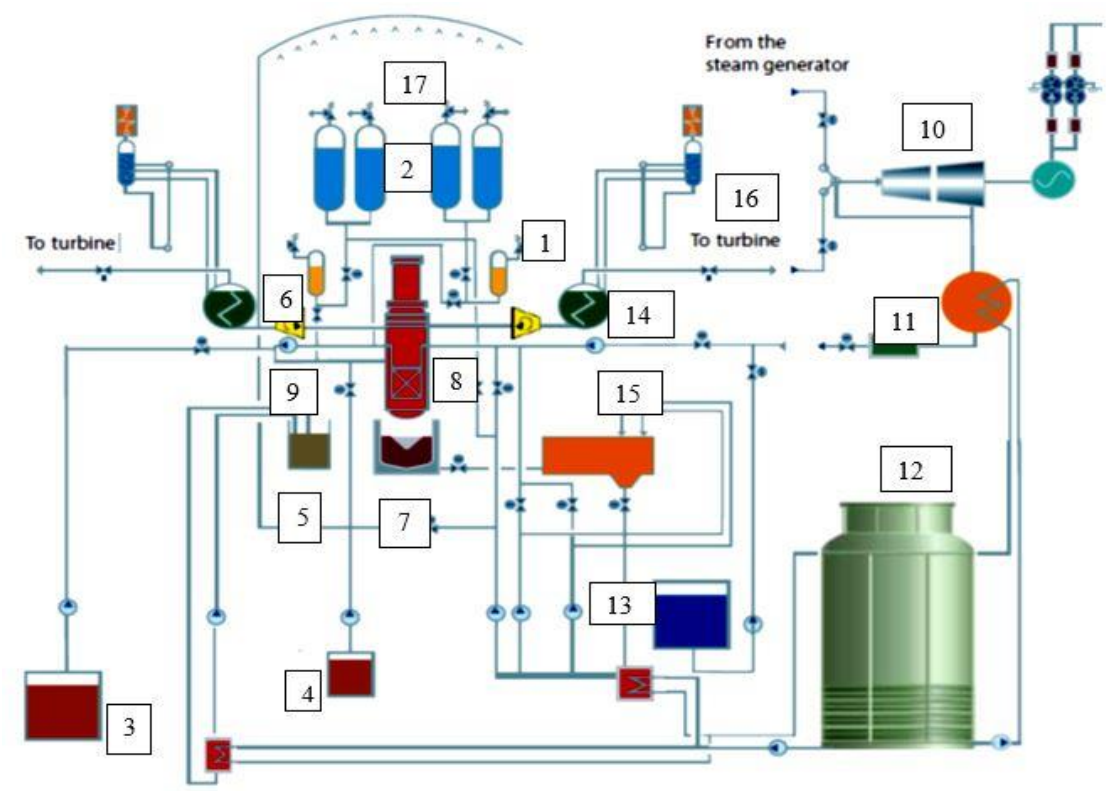

Figure 1: Schematic diagram of simulated small scale water-based reactor; (1) Hydro accumulator-1, (2) Hydro accumulator-2,

(3) Emergency high-pressure boron injection system, (4) Emergency low-pressure boron injection system,(5) Spent fuel pool,

(6) Cyclone, (7) Core catcher, (8) Reactor core, (9) Core coolant circulating pump, (10) Turbine, (11) Heat exchanger, (12)

Cooling tower, (13) Demineralized water, (14) Pressure vessel for making saturated steam into superheated, (15) Main circulating pump, (16) Passive core containment cooling system, (17) Sprinkler system 
Table 1

Key Output Parameters

\begin{tabular}{lccc}
\hline \hline Parameter & Symbol & Value & Unit \\
\hline Heat input & qin & 2514.80 & $\mathrm{~kJ} / \mathrm{kg}$ \\
Heat output & qout & 2116.09 & $\mathrm{~kJ} / \mathrm{kg}$ \\
Net work & Wnet & 398.71 & $\mathrm{~kJ} / \mathrm{kg}$ \\
Thermal Efficiency & $\eta$ & 0.16 & $16 \%$ \\
The mass flow rate of steam & 0 mout & 0.00376 & $\mathrm{~kg} / \mathrm{s}$ \\
Rate of Heat Rejection in Cooling Water & mcooling water & 0.96 & $\mathrm{~kJ} / \mathrm{s}$ \\
The mass flow rate of cooling water from & & & $\mathrm{kg} / \mathrm{s}$ \\
the cooling tower & $\Delta$ Tcooling water & 5.68 & ${ }^{\circ} \mathrm{C}$ \\
Temperature difference at the cooling water & & \\
inlet and outlet & &
\end{tabular}

The heat is first generated in the core and then it heats the water, which goes to the steam generator and generates steam. The produced steam is then transferred to the turbine to rotate and thereby, producing electricity through a generator. After rotating the turbine shaft, the waste heat goes to a heat exchanger by cooling down with the help of the cooling tower. Consecutively, with the help of the distillation again the cooled water goes back to the core.

\section{A. Design Parameter Optimization}

A thermal-hydraulic study has been performed in this work by considering temperature, amount of heat generation, amount of heat release, and flow measurement. Heat transfer used in this study using conduction and convection laws of the heating rod to cladding surface followed by coolant are shown in Equations (1) and (2).

$$
\frac{Q}{t}=\frac{k A\left(T_{2}-T_{1}\right)}{d}
$$

where, $Q$ is the heat transfer, $t$ is the time, $\mathrm{k}$ is the thermal conductivity of the material, $T_{2}$ and $T_{l}$ are the temperatures of corresponding material at the inner and outer surface, and $d$ is the thickness of the material.

$$
q=h_{c} A\left(T_{s}-T_{a}\right)
$$

where, $q$ is heat transfer per unit time, $A$ is heat transfer area, $h_{c}$ is convective heat transfer coefficient $T_{s}$ is surface temperature and $T_{a}$ is coolant temperature. However, one of the important factors of the NPP life cycle is the condition of the reactor pressure vessel (RPV) and its fatigue life. The stainless steel used in this study has been investigated with DPA effect at $823 \mathrm{~K}$ temperature to a neutron fluence of $1 \times 10^{25} \mathrm{n} / \mathrm{m}^{2}$ (Ioka et. al, 2000). DPA generally is defined as displacement per atom is employed to normalize the radiation damage across the reactor containment. Equation (3) is used in this study to determine the thickness of the reactor containment material made of stainless steel.

$$
t=\frac{P_{i} D_{i}}{2 S E-0.2 P_{i}}
$$

where, $P_{i}$ is the internal pressure of the containment, $D_{i}$ is the internal diameter of the containment, $S$ is allowable stress, $E$ is the joint efficiency and $t$ is the material thickness. An ellipsoidal head is chosen with a thickness of $4.053 \mathrm{~mm}$ by using Eq. (3) which is the same as the hoop stress thickness of

the reactor pressure vessel. Since the minimum thickness of the wall chosen is $7 \mathrm{~mm}$, the head thickness of $7 \mathrm{~mm}$ is adequate in this work. Table 1 represents the optimized parameters for developing the small-scale water-based reactor.

\section{B. Development of Physical Model}

The reactor core is divided into two parts- the lower half and the upper half along with an instrumentation channel. The instrumentation channel holds all the thermocouples. The body of the reactor core is constructed with stainless steel consisting of alloy composition of $17-20 \% \mathrm{Cr}, 8-12 \%$ $\mathrm{Ni}$, and $2 \%$ Mo to mitigate the corrosion. The upper half of the reactor core is made with glass to observe the thermalhydraulic properties as well as steam separators. Three flow sensors have been used to measure the flow rate at the inlet and outlet. Basically, they send signals based on the amount of coolant flow. Then the recorded signals are multiplied with the necessary co-efficient to get the exact result. Two pressure sensors have also been used. Two types of safety systems have been utilized in the model: (i) active safety systems, and (ii) passive safety systems. Most of them are worked by a pulse feedback method here. Emergency Core Cooling System (ECCS) with highpressure injection and low power injection module is included in the model. Both have a self-start-up algorithm means that they can work without any human interference. The sprinkler system of the containment is also included in the model which has a total of three stages. Each of the stages contains two sets of the sprinkler system. The whole containment is covered with a total number of six sprinklers. For station blackout, a gravity-driven water supply system is included in the model. It is basically worked by an electromagnet. When station blackout occurs, the electromagnet is demagnetized letting the water flow in the reactor core. Furthermore, an online passive air-cooling system is also integrated into the model. If all electrical components are failed, then the water from the hydroaccumulator is automatically processed to flood the core. 
Each container is filled with 5 liters of water with a flowing rate of 0.3 liters per minute. The heat exchanger used in this study is shell and core type and consisted of sixteen ' $U$ ' loops. A four-stage water filtration system and two-stage containment air filtration systems have also been used in this model.

\section{Development of Control System}

An intelligent control system has been developed by using Microsoft visual basic for controlling the whole system. The code has been developed in the .Net platform. Figure 2 shows the power control flow chart of the overall system. From the figure, it is revealed that the thermocouple starts to measure the temperature after the initiation of the system. Based on the temperature obtained from the experiments, the thermocouple sends a signal to the microcontroller. The microcontroller compares the signal as per set temperature. If the reading matches well then it sends a signal to the controller unit so that the controller unit can readjust the power to maintain the stabilization of the system. Besides the code, all the microcontrollers are programmed with a self-maintained algorithm, from which most of them are PID based. With the help of an electromagnetic relay and using a variable resistor, the power can be controlled from the developed software by using a microcontroller.

Figure 3 shows the power control circuit of the overall system. With the help of a thermocouple, water level sensor, and pressure sensor, the condition of the reactor core is maintained by the microcontroller. Arduino Mega (Mega 2560, $16 \mathrm{MHz}$ ) is used for the experiment. This microcontroller is well known for its reliability along with 54 digital output, 15 analog input and 15 analog output. The microcontroller used in this study has two pulses with a time duration of 3 seconds. If any transient situation occurs, the sensors send the values which are not the same as setpoint values. If only a single pulse comes, the microcontroller considers it as a false count. If the second abnormal pulse is found, then the microcontroller starts the ECCS to maintain the setpoint values, which is programmed using the PID algorithm. If the reactor core pressure rises from a certain level, the high-pressure injection system starts automatically. In this study, K-type (MAX6675) thermocouple is used in the model to achieve the temperature of the heat source. Out of a total of 16 sensors, only 8 sensors are used to take the reading from the reactor core. The readings obtained using sensors are the axial and radial temperature of the core. The thermocouples are calibrated with a mechanical thermometer to get accurate results. Besides, the readings from the thermocouples are directly obtained at a computer monitor where I2C LED (32 bit) monitors are used for getting the same result for the redundancy. An advanced code is developed along with an advanced algorithm based on If-Else (Patnaikuni, 2017). Initially, thermocouples take data from the reactor core and then signals are sent to the microcontroller. Microcontroller analyzes these data, whether they are true or false. If the data are true, then they are displayed on the monitor. If false, then the microcontroller sends back the signal to the source. Besides the core, another 8 thermocouples are used to measure the temperature at the inlet, outlet, turbine, condenser, and cooling tower. Two pressure meters are used to take the pressure data from the core. Furthermore, an air quality sensor is used to analyze the quality of air. Also, several types of active and passive safety systems are included in the study. Most of them are worked by a pulse feedback method.

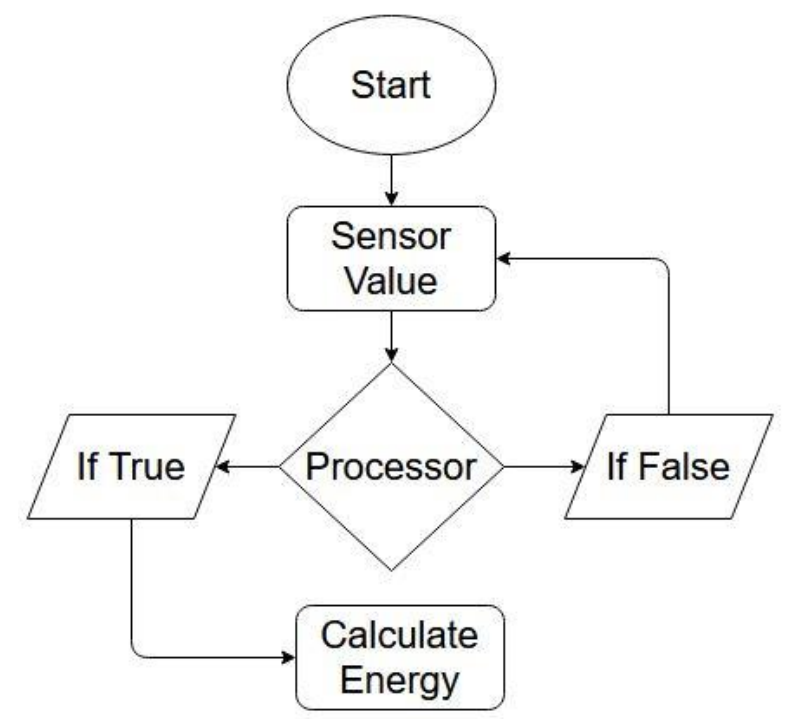

Figure 2: Power control flow chart of the overall system

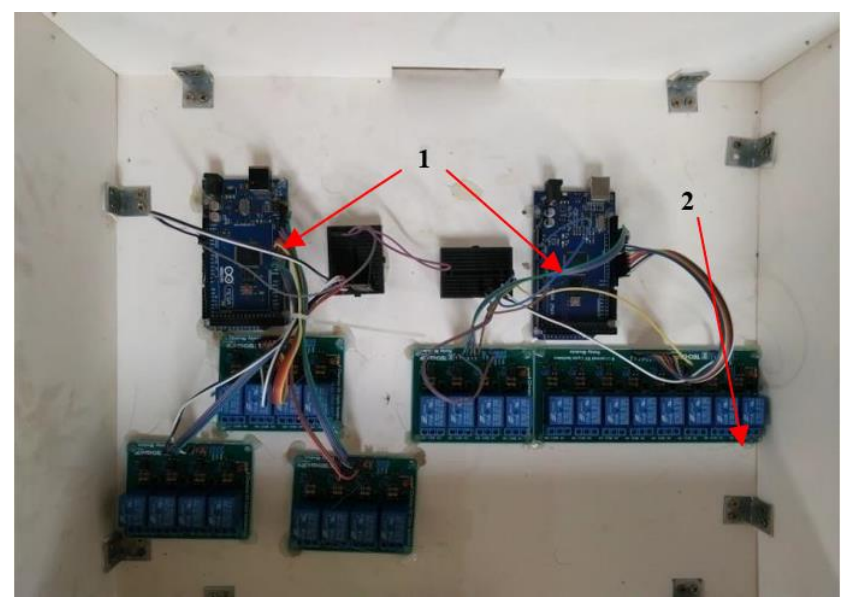

Figure 3: Circuit of control system; (1) Microcontroller, (2) Relay Module

Figure 4 shows the arrangement of thermocouples and heat generation source. Another three of them remain disconnected as back up. Three rows of thermocouples (80 $\mathrm{mm}$ distance) are installed in the core for taking axial and radial temperature distribution. Each row contains three thermocouples of which two are used to take radial temperature, and one is used to take the axial temperature. The mass flow rate of steam is considered as $0.00376 \mathrm{~kg} / \mathrm{s}$ in this study. Since the mass flow rate of steam is very small, the turbine is made as very light weighted. YF-S201 (hall-effect, 15ma-5v) flow sensor is used in this study. Similarly, the network is calculated as $398.70 \mathrm{~kJ} / \mathrm{kg}$ and thereby producing thermal power of $1500 \mathrm{~W}$. 
Figure 5 shows the lower half of the core with the instrumentation channel. The instrumentation channel holds all the thermocouple. The body of the core is constructed with stainless still to mitigate the corrosion. Figure 6 shows the upper half of the core, which is made with glass to observe the thermal-hydraulic properties as well as steam separator. Three flow sensors have been used to measure the flow rate of inlet and outlet for sending analog signals based on the amount of coolant flow. Two pressure sensors have been used to measure the flow rate of inlet and outlet for sending analog signals based on the amount of coolant flow. Six coils are installed for heat generation. Each of them has a 500W capacity. Three of them are in the operational phase for fulfilling the energy supply for the whole system. Figure 7 shows the setup of the developed model. High-pressure injection and lowpressure injection systems work in the same procedure. The only difference from ECCS is that they also take pressure into consideration. Besides, the ECCS and containment spray system and online air filtration system are also included in the model project. The main circulations pump works based on the core temperature. The speed of the pump varies with increasing or decreasing core temperature. The microcontroller takes the temperature data from the core. Then based on the temperature data, it sets the speed of the motor which, is executed by the PWM signal sent to the pump control driver.

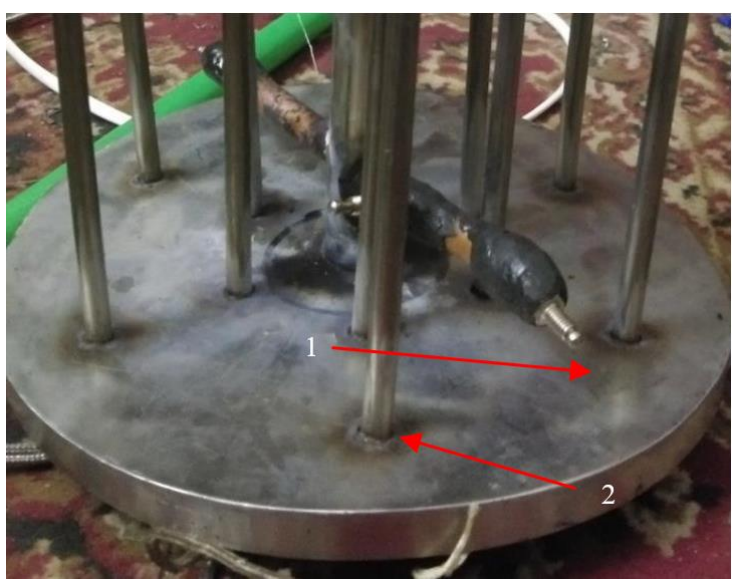

Figure 4: Thermocouple and heat source in the core; (1) Thermocouple, (2) Heat source

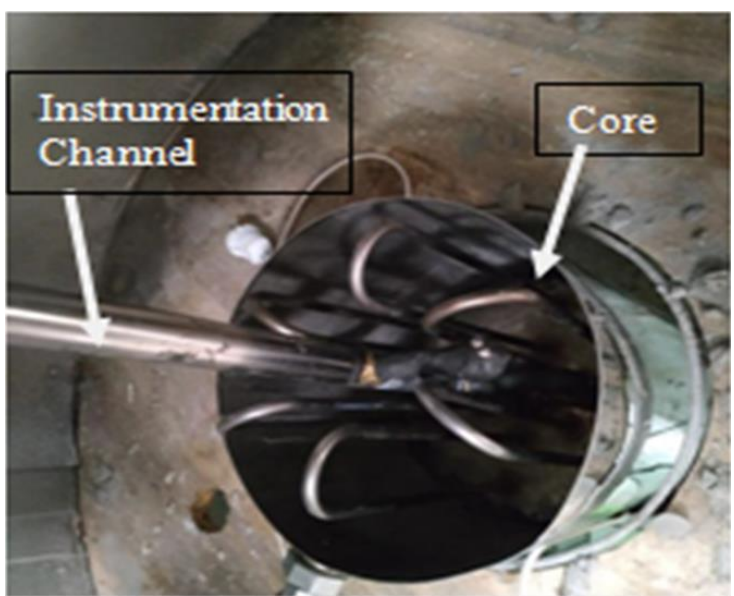

Figure 5: Instrumentation channel and core

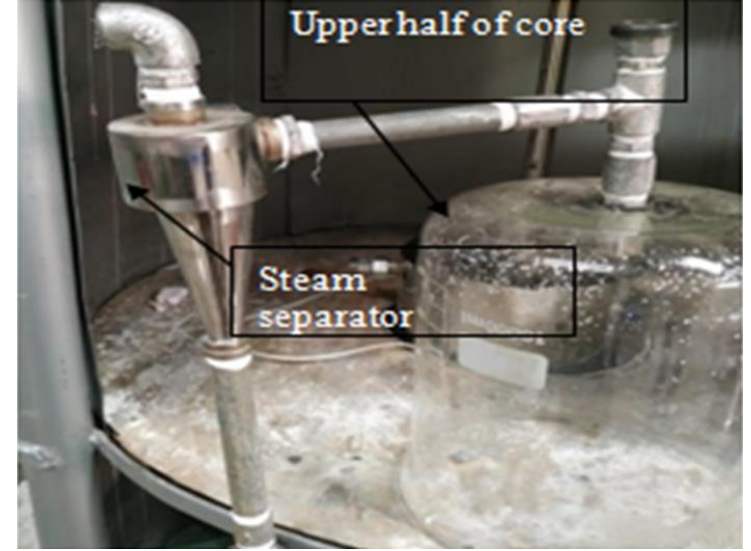

Figure 6: Final setup of the developed model

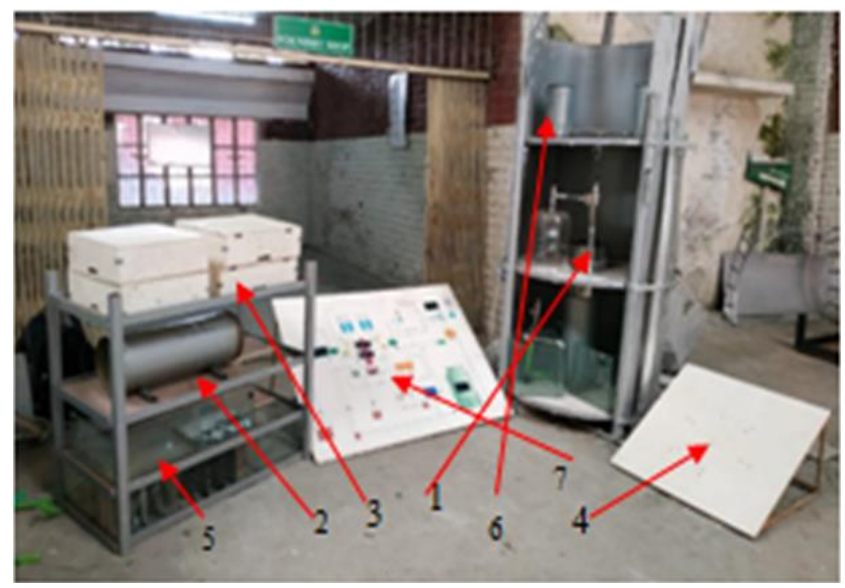

Figure 7: Final setup of the developed model; (1) Core, (2) Heat exchanger, (3) Control system, (4) Heating rod indicator, (5) Distillation and water purification, (6) Hydro accumulator, (7) Display board

\section{RESULTS AND DISCUSSION}

The results obtained from the experimental setup are recorded and plotted in a graphical system. Figure 8 shows the axial and radial temperature distribution over time. The $\mathrm{x}$-axis is denoted as time in s while the $\mathrm{y}$-axis is represented as the temperature in ${ }^{\circ} \mathrm{C}$. The blue line represents the axial temperature with thirty seconds time duration while the green line represents the radial temperature distribution. Figure 8 reveals that the axial and radial temperatures begin to decrease after the creation of an anomaly situation. Figure 9 shows the steam flow rate and water inlet flow rate in $\mathrm{kg} / \mathrm{s}$ in comparison with time in $\mathrm{s}$. A thirty-second time interval is considered for recording data. The blue line indicates the steam flow rate, and the red line indicates the water inlet flow rate. The $\mathrm{x}$-axis is denoted as time, and the y-axis is denoted as a flow rate. Besides, all the safety system works well while operating the system. However, to evaluate the safety system of the model, an anomaly of small break LOCA has been made manually.

Figure 10 represents the relationship between the flow rate of ECCS and the reduction of core temperature with time. It is noticed that the activation of ECCS starts automatically after crossing the core temperature of $97^{\circ} \mathrm{C}$ at atmospheric pressure. According to Westinghouse Technology, the ECCS charging rate is $150 \mathrm{gpm}$. The ECCS is designed by scaling in such a way that it can 
supply a maximum of $5 \mathrm{~L}$ of water per minute, i.e., 0.087 $\mathrm{kg} / \mathrm{s}$ to the core. The transient situation has been made after the functional operation of the reactor with a period of 210 seconds. From Figure 10, it has been observed that the ECCS flow rate is stable during 0 to 210 seconds and no transient situation occurred. However, a transient situation occurred after 210 seconds where the temperature of the core increases suddenly and thereby, starting ECCS. ECCS has been deactivated after 420 seconds as the temperature is decreased and reached under a margin of safety. Similarly, the reduction of decay heat based on the temperature in comparison with time plays an important role. It is noticed that the temperature has increased quickly and reached a peak during the transient period of $210 \mathrm{~s}$ to $420 \mathrm{~s}$. At this stage, the safety system has been started to work and hence the temperature is decreased which represents the reduction of decay heat.

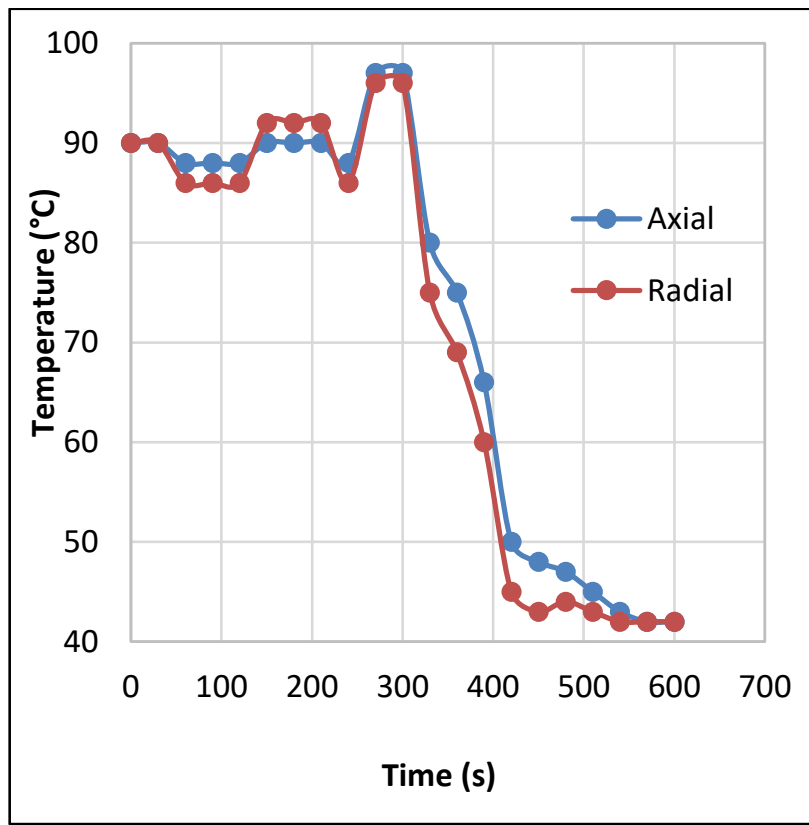

Figure 8: Temperature distribution versus time

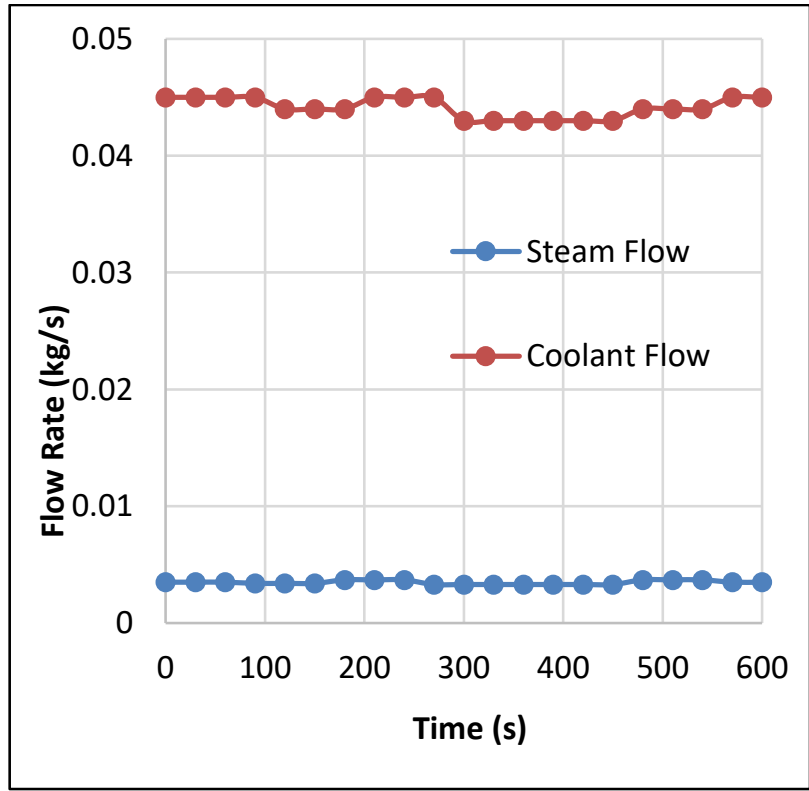

Figure 9: Flow rate of steam and water inlet versus time

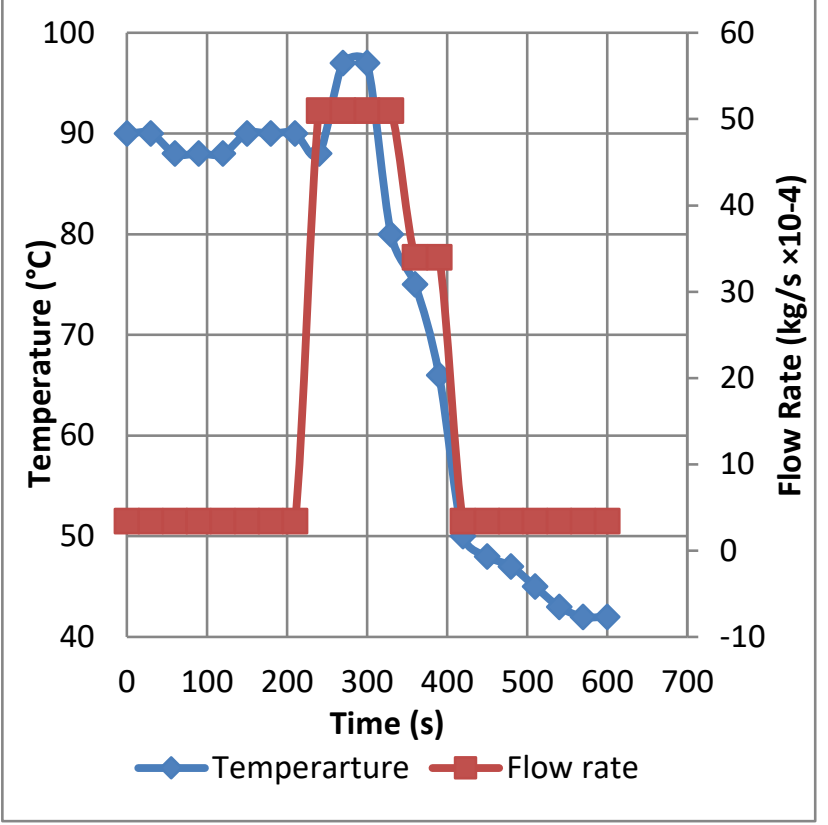

Figure 10: Graphical relationship between the flow rate of ECCS and reduction of core temperature with time

Figure 11 represents the reduction of power load based on the temperature in comparison with time. Surprisingly, the reactor has tripped with the decrease of temperature drastically as the result of transient which results in the reduction of net power. Subsequently, the power is reached to the minimum value, i.e., 0 after $600 \mathrm{~s}$ and thereby, reducing power. From Figure 11 it is seen that power decreases gradually from 210 to 600 seconds

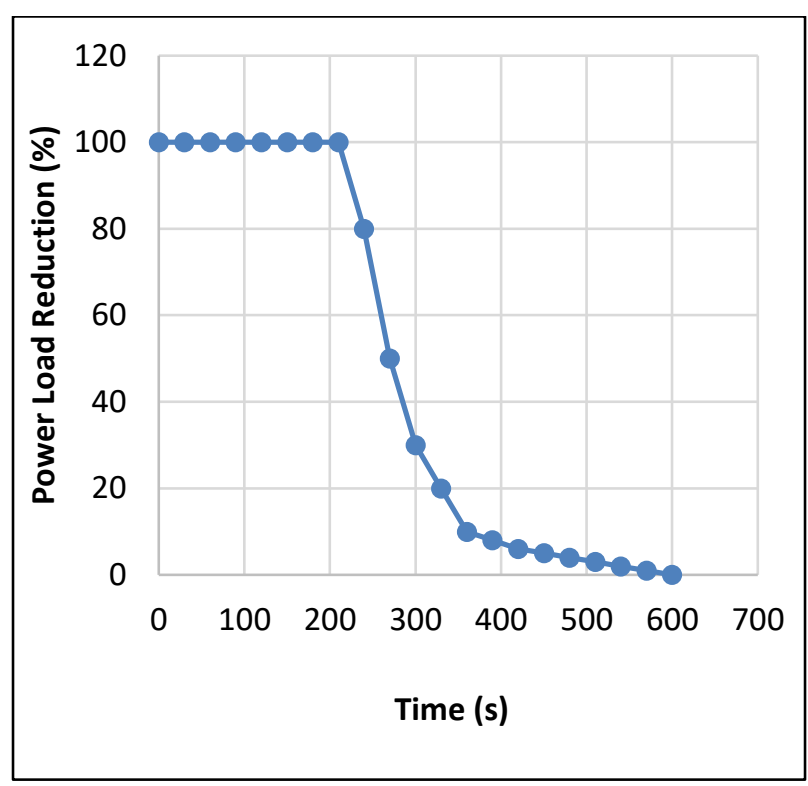

Figure 11: Graphical representation of the power load reduction versus time

after the reactor trip. On the other hand, humidity has been found at a satisfactory level. The reason behind this is that the online water purification and containment airpurification systems work very swiftly. Not only this but also a high-pressure injection system and a low-pressure injection system work perfectly. The gravity-driven hydro accumulator for station blackout also works perfectly 
supplying $2 L$ water during station blackout. The passive heat removal system has been found as working perfectly.

\section{CONCLUSIONS}

The analysis has been performed to evaluate the thermalhydraulic properties of a working reactor model. Theoretical calculations have been performed to construct the reactor model and examine the effect of heat transfer. Temperatures, flow rates, and pressures have been considered as main thermal-hydraulic properties. It is revealed that the system is capable to operate at temperatures between $80^{\circ} \mathrm{C}$ and $120^{\circ} \mathrm{C}$, although the design can withstand up to $200^{\circ} \mathrm{C}$. Similarly, the system can withstand pressure up to $600 \mathrm{kPa}$ though the working pressure is not more than $500 \mathrm{kPa}$. The data of the experiment are taken under the pressure of $200 \mathrm{kPa}$ at $120^{\circ} \mathrm{C}$ temperature. However, error analysis has not been done but data has been repeated six times for which almost similar data has been obtained and found no significant variation. The results show that a heat output of $2116.09 \mathrm{~kJ}$ has been obtained from the system against a heat input of $2514.80 \mathrm{~kJ}$, which gives a network of $398.71 \mathrm{~kJ}$. Furthermore, the efficiency is found as $16 \%$ proving the effective performance of the developed system. However, specific conclusions can be drawn from the study are as follows:

1. The average axial and radial temperatures have been found as $93^{\circ} \mathrm{C}$ and $90^{\circ} \mathrm{C}$ with $0.021 \mathrm{~kg} / \mathrm{s}$ steam outlet and $0.045 \mathrm{~kg} / \mathrm{s}$ water inlet.

2. $0.45-$ watt power has been obtained against the energy insertion of 400 joules at a pressure of $1.5 \mathrm{~atm}$.

3. The developed intelligent control system is highly stable.

\section{ACKNOWLEDGEMENTS}

The authors would like to thank the Military Institute of Science and Technology (MIST) for providing financial support and laboratory facilities.

\section{REFERENCES}

Balonov, M. (2013). The Chernobyl Accident as a Source of New Radiological Knowledge: Implications for Fukushima Rehabilitation and Research Programmes. Journal of Radiological Protection, 33, 27-40.

Breeze, P. (2014). Nuclear power Generation Technologies, Newnes Publication. $3^{\text {rd }}$ Edition, Elsevier Ltd.

Gharib, M., Yaghooti, A. \& Buygi, M. O. (2011). Efficiency Upgrade in PWRs, Energy and Power Engineering, 3, 533536.

Ho, M., Obbard, E., Burr, P. A. \& Yeoh, G. (2019). A Review on the Development of Nuclear Power Reactors, Energy Procedia, 160, 459-466.
Hossain, A., Islam, S., Hossain, T, Salahuddin, A. Z. M \& Sarkar, A. R. (2019). An Intelligent Approach for Thermal-Hydraulic Studies on Safety and Efficiency of Nuclear Power Plant. Energy Procedia, 160, 436-442.

IAEA (2002). Accident Analysis for Nuclear Power Plants. IAEA Safety Reports Series No. 23, IAEA, Vienna.

IAEA (2019). Energy, Electricity and Nuclear Power Estimates for the Period up to 2050. IAEA Reference Data Series No. 1. 2019 Edition, IAEA, Vienna.

Ioka, I., Yonekawa, M., Miwa, Y., Mimura, H., Tsuji, H. \& Hoshiya, T. (2000). Effect of Helium to dpa Ratio on Fatigue Behavior of Austenitic Stainless Steel Irradiated to $2 \mathrm{dpa}$, Journal of Nuclear Materials, 283-287, 440-445.

Khan, A. H., \& Islam, M. S. (2019). Prediction of thermal efficiency loss in nuclear power plants due to weather conditions in tropical region, Energy Procedia, 160, 84-91.

Khan, A. H., Hasan, S. \& Sarkar, M. A. R. (2018). Analysis of Possible Causes of Fukushima Disaster, International Journal of Nuclear and Quantum Engineering, 12(2), 53-58.

Kim, J. S., Park, S. Y. \& Lee, D. H. (2019). Changes and Prospects of Safety Regulation Activities in Korean Nuclear Safety Research, International Journal of Innovative Technology and Exploring Engineering, 8(852), 777-783.

Kojima, T. \& Sato, Y. (2007). Variations of a Passive Safety Containment for a BWR with Active and Passive Safety Systems, Journal of Nuclear Engineering and Design, 237, 74-86.

Miller, K. L. (1994). The Nuclear Reactor Accident at Three Mile Island, Radiographics, 14(1), 215-224.

Nain, H. M. Z., Islam, M. S. \& Khan, A. H. (2019). A Study on Thermal-Hydraulics Characteristics for Designing a Shell and Tube Condenser for a 1200 MWe Nuclear Power Plant. $J$. Bangladesh Acad. Sci. 43(2), 181-189.

P’al, L. \& P'azsit, I. (2009). The Fast Fission Factor Revisited. Nuclear Science and Engineering, 161(1), 111-118.

Patnaikuni, D. R. P. (2017). A Comparative Study of Arduino Raspberry Pi and ESP8266 as IoT Development Board. International Journal of Advanced Research in Computer Science, 8(5), 2350-2352.

Rahman, M. M., Akond, M. A. R., Basher, M. K., \& Huda, M. Q. (2014). Steady-State Thermal-Hydraulic Analysis of TRIGA Research Reactor, World Journal of Nuclear Science and Technology, 4, 81-87.

Sunday, J. I., Daniel, R. E., \& Okibe, A. E. (2013). Simulation of Safety and Transient Analysis of a Pressurized Water Reactor using the Personal Computer Transient Analyzer, Leonardo Electronic Journal of Practices and Technology, 22, 93-105.

Vojackova, J., Novotny, F. \& Katovsky, K. (2017). Safety Analyses of Reactor VVER 1000, Energy Procedia, 127, 352-359.

Wheatley, S. Sovacool, B. K. \& Sornette, D. (2016). Reassessing the Safety of Nuclear Power. Energy Research \& Social Science, 206, 1-5.

Zhen, Y. Q. (2016). Safety and Effective Developing Nuclear Power to Realize Green and Low-carbon Development. Advances in Climate Change Research, 7(1-2), 10-16. 